\title{
Supporting the Next \\ Generation of "Stewards" in Mathematics Education
}

\author{
Barbara and Robert Reys
}

The purpose of doctoral education, taken broadly, is to educate and prepare those to whom we can entrust the vigor, quality, and integrity of the field... Someone who will creatively generate new knowledge, critically conserve valuable and useful ideas, and responsibly transform those understandings through writing, teaching, and application. We call such a person a "steward of the discipline".

Chris M. Golde The Carnegie Foundation for the Advancement of Teaching

Supporting Research, Service and Teaching in Mathematics Education, or STaR, is a program designed to support new faculty who have taken a tenure-track mathematics education position in a U.S. institution of higher education. It is modeled after Project NExT, a successful induction program for early-career mathematicians. Together, these programs strive to meet the goals articulated by Golde in the passage quoted above, albeit with different audiences in mind.

The STaR program was funded in 2009 by the National Science Foundation (NSF) and provides support for three cohorts of STaR Fellows.

Barbara Reys is Curators' Professor of Mathematics at the University of Missouri-Columbia. Her email address is reysb@missouri .edu.

Robert Reys is Curators' Professor of Mathematics at the University of Missouri-Columbia. His email address is reysr@missouri . edu.

The STaR Program is funded by the National Science Foundation under Grant 0922410. The opinions expressed are the authors' and this article does not reflect any endorsement by the National Science Foundation. DOI: http://dx.doi.org/10.1090/noti796
Christine Stephens, St. Louis University, who was instrumental in establishing and maintaining Project NeXT, provided important advice to the program coordinators. The program was also influenced by the NSF Centers for Learning and Teaching (CLT) program that supported doctoral development in mathematics education. ${ }^{1}$

A primary goal of the CLTs was to recruit and prepare doctoral students in mathematics education, addressing the shortage of doctorates in the area that has existed for more than two decades [1], [2], [3], and [4]). In addition, each CLT promoted cross-institutional research collaboration that helped establish professional networks for early-career mathematics educators. One example of this collaboration was initiated by the Center for the Study of Mathematics Curriculum (CSMC), which analyzed state-level mathematics standards in 2006. Faculty members and doctoral students from multiple institutions engaged in work that required reviewing and synthesizing state mathematics standards. One result of this work was the publication of The Intended Mathematics Curriculum as Represented in State-Level Curriculum Standards: Consensus or Confusion? [5]. This research documented the variability of grade-level learning goals in mathematics and promoted discussions that led to the development of the Common Core State Standards Initiative. Similar collaborative work was initiated by other CLTs and helped establish new models for doctoral program development.

\footnotetext{
${ }^{1}$ The CLTs that focused on mathematics education include the Appalachian Collaborative Center for Learning, Assessment, and Instruction in Mathematics (ACCLAIM); the Mid-Atlantic Center for Mathematics Teaching and Learning; the Center for the Mathematics Education of Latinos (CEMELA); the Center for the Study of Mathematics Curriculum (CSMC); and the Center for Proficiency in Teaching Mathematics.
} 
The transition from doctoral student to contributing faculty member is often underestimated. New faculty immediately assume a variety of responsibilities, including collegiate teaching, student advising, service activities with local schools, advancement of a research agenda, and engagement in scholarly writing [6], [7], [8], and [9]). They often do so in an environment where they are alone or among a small number of mathematics educators at their institution. In many cases, their work is different from other colleagues in their home department, which may be mathematics or education. Like Project NExT, the STaR Program provides an opportunity for early-career mathematics educators to discuss challenges they are facing, learn how their colleagues at other institutions are dealing with these challenges, and establish professional and collaborative relationships to advance their work.

More specifically, the goals of the STaR Program are to establish a network of future leaders of mathematics education in order to:

- Provide a support structure for advancing the scholarship of recent doctoral graduates in mathematics education;

- Expand the networking of recent graduates/ advanced graduate students initiated by CLTs to graduates/advanced graduate students from other institutions;

- Showcase research priorities for the field and facilitate the establishment and development of research groups involving young mathematics education scholars from different institutions.

Two specific experiences constitute the nucleus of the STaR Program: a one-week summer institute of STaR Fellows held in conjunction with the Park City Mathematics Institute (PCMI), and a follow-up meeting in conjunction with the annual conference of the Association of Mathematics Teacher Educators (AMTE) the following January or February.

The STaR Summer Institute provides an opportunity for fellows to gather and work together, and it also provides an opportunity to interact with mathematicians and secondary mathematics teachers attending other PCMI programs. Table 1 provides some information about the first and second cadre of STaR Fellows. It also points out one difference between STaR and NeXT Fellows. While Project NeXT Fellows must be employed in a mathematics department, STaR Fellows might have their academic home in a department of mathematics or in a college/department of education.

The first two cohorts of STaR Fellows have reflected on their experiences and the program's impact on their emerging careers. For example, two STaR Fellows commented on how the experience assisted them in transitioning to a faculty position:

I know that my department has invested many resources in hiring me and helping set me on a path toward success in and for the department, but rarely is that investment "matched" by an outside source.... the STaRs program has invested in my growth as a professional, researcher, and hopefully successful tenure-track professor.

Having the opportunity to attend the STaR program has given me an irreplaceable gift as a new academic-a professional learning community in which I can interact and grow. Transitioning from graduate student to professor sometimes seems as if you are traveling the sea without a detailed map, sending out beacons as you navigate between your own personal shift to academia while attending to expectations with which you have little understanding, knowledge or prior experience.

Another STaR Fellow noted how the program gave her a broader perspective of her research agenda:

I feel that the STaR institute provided me with a shift in mindset regarding my short- and long-term goals. Up to this time, I feel like my research has been varied and influenced by the interests of my peers and graduate faculty. Now I see the importance to develop a true research agenda that builds on my prior

\begin{tabular}{|l|c|c|}
\hline & $1^{\text {st }}$ Cadre & $2^{\text {nd }}$ Cadre \\
\hline Number of STaR Fellows & 44 & 37 \\
\hline Number of different institutions awarding their doctorate & 28 & 24 \\
\hline Number of different institutions where they are employed & 42 & 34 \\
\hline Number employed in doctoral-granting institutions & 22 & 18 \\
\hline Number with appointments in departments of mathematics & 24 & 21 \\
\hline Number of females & 32 & 25 \\
\hline
\end{tabular}

Table 1. Background information on the first two cadres of STaR Fellows. 
work. I feel like I am still in the process of developing this, but I am starting to respect the importance of it, and this acknowledgement is a direct result of participating in the STaR program.

Yet another STaR Fellow commented on the long-term impact of the program:

I believe that, twenty years from now, when I look back over my career, I will point to the STaR Program as the source of my focused research agenda, the source of much of my pedagogy, the source of my inspiration, and the source of many enduring relationships.

In closing, we recognize that professionals continue to grow and adapt throughout their careers. It is unreasonable to expect that a Ph.D. program will adequately prepare mathematics educators for the wide range of challenges and expectations they will confront. These inherent limitations of graduate education were conveyed in a summary statement during a recent national conference on doctoral programs in mathematics education:

The U.S. system of mathematics education doctoral studies severely underestimates the depth of training required to do the work of a mathematics educator. If the system is to improve, it must acknowledge the extent of the problem and generate realistic approaches to address it. [10]

The STaR Program is one effort to support the transition path for early-career mathematics educators. ${ }^{2}$ While we are preparing for the third cadre of STaR Fellows, we are also exploring ways of sustaining this effort as the MAA has done for Project NExT. We believe the STaR program, like Project NExT, will have a significant and long-term impact on the profession. As one STaR Fellow put it:

The STaR faculty clearly "paid it forward" during this experience. It was easy to see and understand their love for the field of mathematics educationeach imparting pieces of their expertise, knowing that we as junior faculty will one day lead the field of mathematics education and hopefully mentor those individuals that will one day take our place.

${ }^{2}$ For information about the 2012 STaR application procedures see http://matheddb. missouri . edu/star/.

\section{References}

1. R. E. REYs, Doctorates in mathematics education: An acute shortage, Notices of the American Mathematical Society 47 (2000), no. 10, 1267-1270.

2. ___ Mathematics education positions in higher education and their applicants: A many-to-one correspondence, Notices of the American Mathematical Society 49 (2002) no. 2, 202-207.

3. __ A report on jobs for doctorates in mathematics education in institutions of higher education, Journal for Research in Mathematics Education 37 (2006), no. 4, 262-269, July.

4. __ Jobs in mathematics education in institutions of higher education in the United States, Notices of the American Mathematical Society 55 (2008), no. 6, 676-680.

5. B. Reys (ed.), The Intended Mathematics Curriculum as Represented in State-Level Curriculum Standards: Consensus or Confusion? Charlotte, NC: Information Age Publishing, 2006.

6. R. GLASGOW, An investigation of recent graduates of doctoral programs in mathematics education, University of Missouri, unpublished doctoral dissertation, 2000.

7. B. ReYS, K. M. LLOYD, and M. WinSOR, Induction of doctoral graduates in mathematics education into the profession, U.S. Doctorates in Mathematics Education: Developing Stewards of the Discipline (R. Reys and J. Dossey, eds.), Amer. Math. Soc./Math. Assoc. of Amer., Washington, DC, 2008, pp. 169-176.

8. A. TYMINSKI, Preparing the next generation of mathematics educators: An assistant professor's experience, U.S. Doctorates in Mathematics Education: Developing Stewards of the Discipline (R. Reys and J. Dossey, eds.), Amer. Math. Soc./Math. Assoc. of Amer., Washington, DC, 2008, pp. 223-228.

9. R. E. Reys, D. Cox, S. Dingman, and J. Newton, Transitioning to careers in higher education: Reflections from recent Ph.D.s in mathematics education, Notices of the American Mathematical Society 56 (2009), no. 9, 1098-1103.

10. J. Hiebert, D. LAMBdin, and S. Williams, Reflecting on the conference and looking toward the future, U.S. Doctorates in Mathematics Education: Developing Stewards of the Discipline (R. Reys and J. Dossey, eds.), Amer. Math. Soc./Math. Assoc. of Amer., Washington, DC, 2008, pp. 241-252. 